\title{
Ciências e Saberes tradicionais ${ }^{1}$
}

\author{
P. Justino Sarmento Rezende*
}

\section{Iniciando a conversa}

Quando os colonizadores chegaram ao Brasil (1500) e na Amazônia no século XVI (1542s.) existia uma grande pergunta: se éramos pessoas humanas ou não? A partir daquela concepção se estabeleceu relações de pessoas com não pessoas, superiores e inferiores, de civilizados e selvagens, etc. Assim se tornou normal destruir as culturas, línguas, saberes e matar os indígenas.

Já se foram alguns séculos, mas os preconceitos e estereótipos contra os povos indígenas perduram até nos dias atuais. Os saberes indígenas são vistos com suspeita, com razão, pois os saberes de cada povo indígena servem primeiro para os membros daquele povo e não para todos os povos indígenas nem têm pretensões de serem válidos para o mundo todo e para todas as culturas.

Vou pular grande parte das histórias brasileiras e destaco a Constituição Federal de 1988, que no artigo 231, assegura nossos direitos indígenas quando diz: "São reconhecidos aos índios sua organização social, costumes, línguas, crenças e tradições, e os direitos originários sobre as terras que tradicionalmente ocupam, competindo à União demarcá-las, proteger e fazer respeitar todos os seus bens."

Hoje eu estou aqui compartilhando com vocês alguns saberes, em pleno século XXI, quando o tempo histórico favorece eu contar para as outras ciências e para outros cientistas os nossos pensamentos indígenas. Eu acredito que nós estamos fazendo isso com uma nova perspectiva histórica onde reconhecemos as diversidades culturais, valorizamos o multilinguismo e com possibilidades de construção de novos saberes a partir de nossas relações interculturais.

${ }^{1}$ Este artigo foi elaborado para participação da Mesa Redonda - Ciências e Saberes Tradicionais, dentro da semana de ciências da Universidade Estadual do Amazonas (UEA) com a temática: Educação em Ciências: ciência, sociedade e cidadania na Amazônia, no período de 7-10 out. 2014, na cidade de Manaus.

* É indígena do povo $\forall$ tãpinopona-Tuyuka. É padre salesiano. Possui Licenciatura plena em Filosofia pela Universidade Católica de Brasília. Bacharelado em Teologia pela Faculdade Teológica Nossa Senhora da Assunção. Mestrado em Educação Indígena pela Universidade Católica Dom Bosco, Campo Grande, MS. E-mail: justinosdb@yahoo.com.br

\author{
Tellus, ano 13, n. 25, p. 201-213, jul./dez. 2013 \\ Campo Grande, MS
}


Os saberes que eu vou partilhar com vocês nesse momento pertencem aos povos indígenas que habitam a região do alto rio Negro, Amazonas - Brasil, onde vivem vinte e três povos pertencentes a quatro famílias linguísticas: Tukano, Aruak, Maku e Yanomami.

\section{Somos pessoas inteligentes}

Para tratar dos Saberes de um povo eu parto do princípio de que as pessoas são inteligentes, são capazes de enxergar o mundo, de enxergar as pessoas, perceber os desafios históricos, sabem dar respostas para os desafios de cada momento histórico. Nós indígenas estamos dentro deste panorama. Nossos avós construíram muitos saberes que sustentaram e sustentam os povos indígenas e suas culturas. Nossos avós ensinavam todos esses saberes cotidianamente e nas grandes festas.

Como eles ensinavam? Segundo aquilo que eu sei os nossos avós e pais nos ensinavam falando-mostrando-fazendo e aprendemos ouvindo-vendo-fazendo. Os nossos educadores são os nossos pais, avós, sábios de nossas culturas. São pessoas conhecedoras dos fundamentos da educação de seu povo, possuem suas filosofias de vida, construíram suas próprias teorias de conhecimento e práticas de vida, os conhecimentos indígenas são organizados, transmitidos de maneira organizada e diferenciada para crianças, jovens, meninas, meninos e adultos [ ler anexo 1: NOSSAS VIDAS INDÍGENAS]

\section{Saber cuidar das vidas}

Nossos saberes indígenas estão intimamente ligados com as vidas. Nossos avós nos ensinanaram que nós pessoas humanas vivemos relacionando com muitas outras vidas: vida humana (outra etnias), vida do mundo que nos sustenta (terra, água, ar...), vida das florestas [gente-florestas], vida das águas, dos peixes [gente-peixes], gente pedras, etc. Tudo o que nos circunda e envolve são outras vidas dialogantes com seres humanos. [ler anexo 2: ÁRVORES]

Os nossos sábios avós nos ensinam que a vida humana deve ser bem cuidada com os bens materiais e bens imateriais. Deve ser bem cuidada desde a gestação, por isso, os benzedores benzem o corpo, o útero e a vida da mãe para que o novo ser em gestação possa crescer bem. Assim em todas as fases da vida da vida até a nossa morte.

Quando eu falo de bens materiais estou me referindo à alimentação (comida, bebida), cuidado com o corpo (banho, descanso, trabalho...), com o ambiente, etc. Os bens imateriais são os benzimentos que são feitos para criar harmonia de nossos interesses e possibilidades, criar harmonia de nossa vida 
humana com as vidas de outras pessoas e outros seres vivos presentes nas florestas, nas águas, nas montanhas, etc.

Os benzedores benzem para criar equilíbrio nos relacionamentos com diversas vidas. Quando os seres humanos desrespeitam os ambientes sagrados ai surge desarmonia e desequilíbrio, que se expressa através de temporais, doenças, acientes de trabalho, etc. Os meus parentes Tuyuka até hoje fazem as festas cerimoniais de cantos/danças, discursos, pinturas, benzimentos, defumação para criar harmonia entre as pessoas. Eu também já participei diversas vezes. Passei noite acordado para participar das festas, dancei as danças mais simples como cariço. Atualmente vivo mais tempo com o povo Yanomami do rio Marauiá, no município de Santa Isabel do Rio Negro. Lá os pajés fazem seus rituais diariamente, cheiram paricá, entram em transe, dança, conversam com as divindades para pedir às divindades para que criem harmonia e equilíbrio no convívio das pessoas, pedindo proteção para que não aparecçam doenças, que afastem temporais, raios, etc. Fazem danças para cura de doenças; as mulheres de vez em quando acordam gritando e correm no meio do mato com galho na mão para espantar os espíritos da doença.

Como são produzidos os saberes? São produzidos por todas as pessoas, mas principalmente por pajés, mestres de canto/danças e demais benzedores. Eles possuem inteligência e sensos apurados para conhecerem o mundo material e imaterial. Por isso dizemos que existem os saberes materiais práticos e os saberes imateriais práticos. Os nossos avós aprofundavam seus conhecimentos do mundo das pessoas, do universo, das florestas, dos rios e outras vidas. Refletiam individual e coletivamente, faziam meditações noturnas e conversavam sobre o funcionamento dessas realidades. A partir disso, eles produziam seus pensamentos e ensinavam as práticas de boa convivência com os mundos que nos cercam. No cotidiano e nas festas os sábios sentam-se na casa do baya (mestre de cantos/danças; ou na Casa de Saberes), mascam ipadu, fumam o cigarro, passam um para o outro esses elementos geradores dos saberes. Nas festas rituais conversam de forma solene, porém, são intercaladas entre falas sérias com gostosas piadas. As seriedades, brincadeiras, gargalhadas, apelidos são ingredientes que dão bom sabor aos ambientes dos saberes. As mulheres possuem seu próprio campo para produção dos conhecimentos sobre a feminilidade e todas as ações que elas desenvolvem no mundo e em suas vidas.

Além desses sábios de realidades sagradas existem outros grandes conhecedores das realidades da pesca, da caça, conhecedores de geografias regionais, conhecedores dos igarapés, conhecedores das vidas dos animais, seus caminhos, conhecem épocas de frutas, das caças e sua alimentação. Existem sábios de pinturas, de tocar os instrumentos musicais. Existem sábios (as) que conhecem diversos remédios de nossas florestas que servem para curas 
de diversas doenças, para atração da pessoa amada, para ser bom pescador, bom caçador, etc.

Saberes também são os segredos que os sábios transmitem somente para seus filhos e netos. Os saberes constituem também diversas formas de colocar em comum os seus conhecimentos a serviço do seu povo.

Anoto aqui alguns cantos/danças [Basamo = conjunto de Músicas/ Cantos] que se realizam para cuidar das vidas, estão relacionados à vida humana e ao mundo material e imaterial que nos envolvem. Essas vidas são temidas, reconhecidas, respeitadas, invocadas, faladas, benzidas, cantadas e dançadas. Entre os Tuyuka existem esses cantos e danças importantes:

DASIA BASA (Dança do Camarão): é cantada e dançada quando dá primeira menstruação das moças, quando se quer dar nome a um filho ou filha de um chefe e quando vão dar de comer peixe pela primeira vez a essa criança. HIÃ BASA (Dança da Lagarta): como o Dasia basa, é cantada e dançada durante a cerimônia de dar nome a uma criança, na primeira menstruação da moça e de dar de comer peixe. Dançada e cantada durante o verão Hiarõ que significa "tempo de aparecimento de lagartas que comem folhas de cunurizeiro". Eles representam espíritos de pajés do universo e provocam trovoadas e doenças nas pessoas. Através dessa dança/canto os benzedores protegem as comunidades fazendo apaziguamento dos seus espíritos. IKIGA (Dança Inajá): cantam e dança na cerimônia de oferecimento de comida (dabucuri, na língua geral), como peixe, produtos de mandioca e carne de caça. A origem da cerimônia e do canto vem dos seres divinos Diroa-masã, quando eles fizeram a primeira cerimônia de oferecimento de comida, peixe e caça para seus avôs. UMUA BASA (Dança do Japu): assim como a dança do Camarão, é cantada nas cerimônias de nominação e de proteção da casa e, por extensão, de toda a comunidade. WAI BASA (Dança do Peixe): é cantada e dançada antes da época das enchentes, quando os peixes se juntam e fazem sua desova. Serve para apaziguar os espíritos dos peixes (Wai masã), para não provocarem doenças na humanidade. WASÕ BASA (Dança de Wasõ): cantada e dançada quando se faz oferecimento de frutas, como açaí, buriti, ingá, ucuqui, cunuri, jatobá, japurá, uacu, tucumã, sorva, sorvinha, cucura, etc. ÑASA BASA (Dança do Maracá): cantada e dançada na festa de confraternização durante a qual se protegem as pessoas e suas casas contra doenças do universo e as enviadas pelos pajés e os espíritos da floresta. YUA BASA (Dança do Calanguinho Azul): cantada e dançada após concluir os trabalhos das roças. Pedem aos espíritos para que haja um bom verão para boa queimada. Cantam e dança pedindo para que não apareçam doenças às mulheres durante seus trabalhos. YUKU BASA (Dança dos Paus): cantada e dançada como complemento da dança Yua Basa. KAMÕKA BASA (Dança do Kamõka): é cantada e dançada nas festas com os membros da Casa Ritual e os demais irmãos. Servem para 
benzimentos de proteção de seus moradores contra doenças, picadas de cobra e acidentes de trabalho.

Existem outros instrumentos musicais mais simples que são utilizadas em meio as músicas sagradas. Alguns são: $\mathbf{S u}$ (caracol), ñama koã (flauta de osso de veado), ñama dupoa (flauta de cabeça de veado), kuware (casco de jabuti), weru weru hiri koã (flauta de osso de anta), perurige (flauta de pã), tõrõriwu (flauta de taboca) e seruru hirõ (flauta de pã pequena). [ler anexo 3: DANÇA]

\section{Nossas origens divino-humanas}

Segundo as narrativas das histórias do povo Pamuri Basoka [povos que emergiram da água] as Casas do Surgimento marcam o início de nossas histórias sagradas. Nossos mestres de danças/cantos narram que existem duas Casas inicialmente: Opekõwi $=$ Casa de Leite; Tõkowi $=$ Casa de bebida doce $[$ do Bem]. Ao lado dessas Casas existe um lago Opekõtaro = Lago de Leite. Tenório $(2005,11)$ diz: “Tetiro to niku marĩya tokõ kosope, marĩya tokõwi, marĩya tokõkumuro, marĩya tokõwastoa, tie niku ku Utapinomakн niñamasãre" ${ }^{2}$. As histórias de nossas origens estão bem ligadas às divindades geradoras da vida. Por outra parte existem longas Rotas de Emergência ou Transformação dos povos indígenas, por isso, são muitas Casas de Transformação pelas quais passamos até estabelecermos nas atuais moradias. Essas histórias são transmitidas no dia a dia aos filhos e netos. A forma solene de narrar essas histórias acontecem nas cerimônias de cantos e danças rituais: discursos, entoações, etc. São momentos sagrados por isso, antes, durante e depois os mestres de danças, cantos e pessoas que consomem bebidas e comidas benzidas seguem dietas alimentares recomendadas pelo benzedor principal.

Os nossos nomes de benzimentos estão enraizados numa das Casas de Transformação. Nós Filhos-da-Cobra-de-Pedra ${ }^{3}$ - chegamos à Cachoeira de Caju $\mathrm{u}^{4}$ como um só grupo. Ai construíram Basawi (Casa Ritual) e os primeiros seres emergentes (primeiros Tuyuka) realizaram rituais de iniciação de todos

\footnotetext{
${ }^{2}$ Marĩya tokõkosope $=$ nossa porta do bem [porta do bem, doce]; marĩya tokõwi $=$ nossa casa do bem [doce]; marĩya tokõkumuro = nosso banco do bem [doce], marĩya tokõwatoa $=$ nossa cuia do bem [doce]; tie niku ku Utapinomaku niñamasãre = são esses elementos que dão vida ao Filho-da-Cobra-de-Pedra. Tradução do texto: Por isso ai estão nossa Porta do Bem, nossa Casa do Bem, nossa Banco do Bem, nossa Cuia do Bem, esses elementos constituem a vida do Filho-da-Cobra-de-Pedra.

${ }^{3}$ Utapinopona é o povo popularmente conhecido como Tuyuka. Nome sagrado: Utã = Pedra; Pino = Cobra; Pino = Cobra; Filhos-da-Cobra-de-Pedra .

${ }^{4}$ Essa Cachoeira está localizada no território colombiano no alto Uaupés. Também chamada Cachoeira de Jurupari.
} 
os seus filhos, utilizando instrumentos cerimoniais, flautas sagradas, adornos de cabeça ou faixas emplumadas, benzimentos, entoações, cantos, caapi. Dentro da Casa Ritual através de discursos entremeados de cantos, danças e brincadeiras, narram histórias sagradas passando pelas diversas Casas de Transformação.

Nós povos indígenas temos raízes de nossas vidas nos seres divinos. Existem pensamentos e práticas teológicas próprias de cada povo indígena. Cada povo possui centenas de espiritualidades que sustentam suas vidas, suas histórias, seus projetos de vida, seus trabalhos, suas festas. Existem rituais, cerimoniais, disciplinas, dietas alimentares, etc.

Nós indígenas temos nossos teólogos, espiritualistas, que meditam, refletem, os que benzem, que curam, que dançam, fazem discursos rituais, realizam cerimoniais... Eles falam das histórias de vida, histórias das vitórias, das superações e ultrapassagens dos perigos, dos inimigos. Eles cantam sobre as vidas, sobre as histórias! Ritualizam as nossas histórias. Através dessas cerimônias e rituais acontecem as ações preventivas, curativas de seres divinos que os nossos antepassados depositaram suas vidas, suas histórias e seus projetos de vida.

Cada povo indígena é específico, com seus saberes, conhecimentos, danças/cantos, rituais, línguas, modos de interagir com as pessoas e com mundo envolvente. Entre os membros de um mesmo povo somos irmãos maiores e menores, tios, avós... Com as pessoas de outros povos indígenas podemos ser cunhados, primos. Esses saberes já vieram de longe, desde nossos antepassados seres-divinos-espíritos até chegar aos nossos tempos contemporâneos.

\section{Modos de educar}

Nossos avós e nossos pais nos ensinaram que a educação serve para nos ensinar a ser GENTE, ser PESSOA HUMANA. Por isso, eles cuidam de nós e ensinam muitos conhecimentos de como viver a vida, como viver com as pessoas, como tratar as pessoas, como trabalhar, como pescar, como caçar, como dançar, como casar, como educar os filhos, como acolher as pesssoas, etc.

Nossos avós possuem diversos conhecimentos (conteúdos), diversos modos de cuidar da pessoa (pedagogia) e diversas forças imateriais (benzimentos, forças das divindades) para cuidar da pessoa do educador, dos filhos e da comunidade, dos ambientes [casas, florestas, caminhos, roças, rios...]. A meta da educação é educar para que o filho e a filha cheguem a ser bons membros do povo ao qual eles pertencem. Finalmente, que ele e ela saibam viver bem. 


\section{Fechando a conversa}

Concluindo as colocações dos meus pensamentos digo que hoje em dia não é possível dizer categoricamente que somente os saberes tradicionais indígenas serão soluções para os problemas do mundo nem tão pouco dizer que somente os saberes ocidentais [não indígena] é que resolverão os nossos problemas. Eu vejo o mundo material e imaterial hoje está pedindo ajuda para continuar existindo melhor. Nós indígenas que moramos lá no interior, dentro das florestas sofremos também com as consequências da destruição humana da biodiversidade, da natureza, da floresta, da poluição, etc.

Nesses últimos quinze anos em nossa região, do alto rio Negro, se buscam recuperar os saberes de nossos avós que foram sendo deixados de lado desde que começou o processo de escolarização, na década de 1920. Gradualmente nós indígenas do rio Negro fomos estudando outras ciências ocidentais, de tal maneira que pensávamos que estudando tais ciências não precisaríamos mais dos nossos saberes tradicionais. Mas sem esses saberes nossas vidas indígenas tiveram muitos vazios que nem ciências modernas ocuparam e substituíram.

Eu transito muito nessa nossa região, participo dos diversos seminários de educação promovido pela Federação das Organizações Indigenas do Rio Negro (FOIRN) em parceria com o Instituto Socioambiental (ISA), ministro cursos na Licenciatura Indígena Políticas Educacionais e Desenvolvimento Sustentável - ICHL; UFAM -, nos polos espalhados na nossa região, vejo as escolas indígenas realizando diversas pesquisas em suas conclusões de trabalhos de cursos com os temas de saberes tradicionais. Algumas escolas indígenas possuem pesquisas muito bem feitas a respeito da Geografia regional, sobre os lagos, procriação de peixes, estudo das constelações, plantações, vegetações, benzimentos, danças/cantos, etc. Tais estudos são feitos utilizando métodos de pesquisas modernas: observação, anotações, estatísticas de resultados, comprovação de resultados e divulgação. É importante dizer que no tempo chamado "hoje" as ciências modernas influenciam positivamente no conhecimento de nossas vidas indígenas e do mundo. Os professores, alunos e os membros das comunidades realizam pesquisas com metodologias científicas de pesquisa-ação, estatísticas e comprovando a veracidade de suas pesquisas a respeito das mesmas realidades que nossos avós vinham ensinando oralmente e com a prática.

Por fim, digo que as Ciências e Saberes Tradicionais são dois campos de saberes que se complementam e podem ajudar muito no cuidado das vidas e do mundo em que vivemos. Nós membros dos povos indígenas acadêmicos, professores, educadores, pessoas que ocupam cargos públicos não podemos nos omitir de contribuir com os nossos saberes na tarefa de cuidar da vida e 
do mundo. Para isso temos que amar a nossa vida indígena (ler o anexo 4: É BOM SER INDÍGENA).

\section{Bibliografia}

ANDRELLO, Geraldo. Rotas de criação e transformação: narrativas de origem dos povos indígenas do Rio Negro. São Paulo: Instituto Socioambiental; São Gabriel da Cachoeira, AM: Federação das Organizações Indígenas do Rio Negro - FOIRN, 2012.

CABALZAR, Aloisio (Org.). Manejo do mundo: conhecimento e práticas dos povos indígenas do Rio Negro, Noroeste amazônico. São Paulo: Instituto Socioambiental ISA; São Gabriel da Cachoeira, AM: Federação das Organizações Indígenas do Rio Negro - FOIRN, 2010 (Conhecimentos indígenas, pesquisas interculturais; 1).

CABALZAR, Aloisio (Org.). Peixe e gente no Alto Rio Tiquié: conhecimentos tukano e tuyuka, ictiologia, etnologia. São Paulo: Instituto Socioambiental, 2005.

DIAS CABALZAR, Flora (Org.). Educação Escolar Indígena do Rio Negro, 1998-2011: Relatos de experiências e lições aprendidas. São Paulo: Instituto Socioambiental; São Gabriel da Cachoeira, AM: Federação das Organizações Indígenas do Rio Negro FOIRN, 2012.

RAMOS, José Barreto (Org.). Utapinopona kuye Poseminiã Niromakaraye. São Paulo: Instituto Socioambiental; São Gabriel da Cachoeira, AM; Associação Escola Indígena Utapinopona Tuyuka - AEITU, 2012.

REZENDE, J. S. A educação na visão de um Tuyuka. Manaus: Faculdade Salesiana Dom Bosco, 2010.

TENÓRIO, Higino Pimentel (Org.). Wiseri Makañe Niromakañe - Casa de transformação: origem da vida ritual Utapinopona Tuyuka. São Gabriel da Cachoeira, AM: Associação Escola Indígena Utapinopona Tuyuka - AEITU; São Paulo: Instituto Socioambiental, 2005.

\section{Anexos}

\section{1 - NOSSAS VIDAS INDÍGENAS}

Escritor: Justino S. Rezende. Produção: junho/2013

Saudades dos indígenas imaginários do passado!

Lá muito longe, um tempo muito tempo atrás,

Quando vivíamos somente nós indígenas em nossas terras,

Como era diferente de hoje!

Nós vivíamos as nossas riquezas.

Vivíamos as nossas simplicidades, pobrezas, alegrias. 
Nossa nudez significava nossa originalidade, beleza, dignidade, indianidade. A nossa nudez não era sinônimo da pobreza.

Era nosso estilo de vida, naquelas histórias, exibição do corpo humano-divino. Contávamos histórias que eram somente nossas.

Ouvíamos atentos sentados, deitados nos nossos bancos, redes de fios de buritizeiro.

Ouvíamos histórias que despertavam vontade de conhecer as personagens.

Ouvíamos histórias assustadoras e ficávamos arrepiados.

Vivíamos dia a após dia na tranquilidade.

Diariamente saíamos em busca de nossa alimentação.

Alimentação espalhada nas grandes florestas,

Nas nossas pequenas roças.

Nas florestas em cada estação encontrávamos frutas gostosas.

Nos caminhos das coletas nossos cachorros caçadores,

Encontravam cutias, pacas, queixadas, caititus, quatis, macacos...

Pescávamos os peixes com arco-flecha, fruta-veneno-de-peixe...

Com as zarabatanas, armadilhas matávamos mutuns, inambus, jacus...

Fazíamos festas rituais masculinos, femininos.

Festas longas, cheias de benzimentos de apaziguamentos das doenças,

Benzimentos de curas, prevenção das doenças...

Andávamos pintados com urucum, jenipapo, carajuru,

Andávamos com os nossos corpos com odores das puçangas,

Para pegar peixe, caça e também pessoa desejada.

Traçávamos com nossas mãos artistas,

Linhas avermelhadas de urucum em nossos belos rostos.

Ficávamos orgulhosos com pinturas e seus simbolismos.

Nossas pinturas faciais e corporais,

Colocavam em contatos com as forças divinas,

Contatos com as forças da natureza: gente-florestas, gente-peixes...

Casávamos com gente certa, prometidas desde ventre materno.

Visitávamos nossos parentes, irmãos, cunhados, tios...

Levávamos nossas riquezas para outros povos,

Fazíamos nossas festas de ofertas-dabucuri.

Recebíamos em trocas outros produtos.

Bebíamos bebidas fermentadas e alucinógenas,

Que nos levavam para os mundos das sabedorias.

Entrávamos em transe,

Conversávamos com os espíritos da vida-deuses. 
Bebidas alucinógenas, caxiris, cigarros benzidos, Conduziam-nos até às nossas Casas de Origem, Nas Casas dos Trovões, Casas de Pedras Quartzo.

Assim ficávamos conscientes de sermos donos de saberes, conhecimentos, Que recebemos por iluminação durante nossas meditações cotidianas, noturnas, da madrugada.

Somos amigos, irmãos, primos, cunhados, netos da natureza, das águas, dos trovões, das cobras grandes, dos seres vivos originadores das vidas indígenas. Assim éramos nós.

Depois de grandes rituais tínhamos um tempo de descanso,

Para dormir à vontade, recuperar nossas energias, forças.

Refeitos seguíamos novamente ao movimento da nossa vida.

\section{2 - ÁRVORES}

Escritor: Justino S. Rezende. Produção: junho/2012

As árvores são vidas,

Como nós seres humanos.

As árvores são gentes,

Como nós seres humanos.

Árvores nascem, crescem e morrem,

Como nós seres humanos.

Possuem pais, mães, avós, parentes,

Como nós seres humanos.

Brotam, crescem, amadurecem, dão frutos,

Como nós seres humanos.

Seus frutos bons dão sabor para muitas vidas,

Como nós seres humanos.

Ficam alegres, tristes, choram,

Como nós seres humanos.

As árvores são originais e únicas,

Como nós seres humanos.

Árvores têm amigos e amigas,

Como nós seres humanos.

As árvores cuidam-se para se tornarem elegantes,

Como nós seres humanos.

As árvores crescem e vivem livres,

Como nós seres humanos. 
As árvores possuem longas e belas histórias,

Como nós seres humanos.

As árvores são riquezas do mundo,

Como nós seres humanos.

As árvores sabem acolher outros seres nos seus galhos, folhas e sombras,

Como nós seres humanos.

As árvores sabem respeitar outros seres vivos,

Como nós seres humanos.

As árvores querem continuar vivendo felizes,

Como nós seres humanos.

Eu quero viver bem com toda a natureza.

Quero ser cada vez mais humano.

Amigo de todos, do bem e da vida!

\section{3 - A DANÇA}

Escritor: Justino S. Rezende. Produção: agosto/2012

Danças! Inúmeras danças do universo!

Os sons da natureza e dos seres vivos produzem diversas melodias e ritmos. A criação toda participa da grande dança das vidas!

Nossa vida segue a dança, ritmo, parada, silêncio...

Dança é a essência da existência, das histórias.

Essência dos seres viventes.

A fonte das danças está mesmo no Criador!

Desde os minúsculos até os gigantes animais,

Movimentam-se no ritmo de danças da vida.

As formigas dançam enfileiradas nos caminhos,

Nas pedras, nas florestas, nas árvores.

Os peixes dançam correndo em grupos pelos rios, lagos, praias, cachoeiras, Fazem suas piracemas, suas festas rituais.

Os pássaros de diversas espécies gritam, voam,

Fazem zig-zag nos ares, em cima dos rios, lagos, entre as árvores.

Os diversos animais pulam nas florestas e nas árvores, gritam, cantam.

Os sapos pulam de um lado para outro,

Dançando suas danças e suas músicas.

São infinitos motivos para as danças.

Os ritmos e melodias saem de dentro dos corações, dos sentimentos, emoções.

Os seres humanos são produtores de músicas, ritmos, melodias e danças. 
Expressam sentimentos de alegria, paz, dores,

Decepções, frustrações, realizações, medos,

Esperanças, desejos, pedidos, súplicas.

Os corpos movimentam-se de acordo com os ritmos.

Os sons, músicas e instrumentos são construídos nas histórias.

Os ritmos mexem os homens e as mulheres por dentro e por fora,

Dançam suam, cansam e realizam-se.

Os povos indígenas dançam,

Tocam instrumentos e acompanham seus pares.

Cantam, dançam, gritam e pisam forte no chão da vida.

Expressam suas alegrias, tristezas, pedidos, emoções.

Envolvem a natureza que os sustenta em suas danças.

As danças corporais deixam ligado o homem e a mulher com a vida.

Dançam pelos acontecimentos da natureza, da vida, da história, da morte...

As danças nos deixam cansados e realizados,

Deixam-nos extasiados, transformados, alegres, satisfeitos, leves.

As danças simbolizam o entusiasmo pela vida.

As danças são mistérios, são forças que nos envolvem

E mostram outros sentidos da vida.

Somente quem já dançou pode dizer o que significa dançar.

As músicas e danças existem antes que nós existíssemos.

Continuarão existindo sempre.

Quem se aventura a dançar faz sua própria experiência.

Faz a sua própria escolha.

Em algumas culturas não se escolhe para dançar,

Somos obrigados pelas tradições culturais.

Muitas pessoas já carregam dentro de si a força da dança.

A dança, os ritmos e as melodias já nascem em suas veias.

Muitas pessoas lançam-se no mundo da dança naturalmente.

Essas pessoas gostam, adoram, amam dançar!

Músicas, ritmos, melodias, dançadores interagem harmoniosamente.

Para alegrar o mundo, a natureza, o Criador!

\section{4 - É BOM SER INDÍGENA}

Escritor: Justino Sarmento Rezende. Produção: abril/2014

Ser indígena é muito bom!

É ser pessoa especial e única no mundo. 
Com a gente o mundo fica mais bonito.

O nosso carinho e amor deixam o mundo mais sorridente.

Nossos saberes e conhecimentos,

Nossas culturas enriquecem o mundo.

A FOIRN durante 27 anos está falando disso.

Homens e mulheres especiais, iluminadas,

Fortes, corajosas e vencedoras,

Lutaram pelos nossos povos.

Sonharam alto, pelo bem dos outros.

Continuamos fortalecendo nossas identidades culturais

E, nossas diferenças culturais.

Porém, juntos devemos vencer as forças negativas,

Que querem anular as nossas identidades e nossas diferenças.

Devemos ultrapassar os desafios de cada momento.

Entre tempos e contratempos,

Temos que continuar fortes.

Dia 30 de abril de 1987 é a data da nossa VIDA!

Começo da nova história!

Fortes nas nossas identidades

Aprendamos a interagir com as diferenças culturais,

A Família FOIRN é grande.

Seus filhos espalham-se por todos os espaços.

Nas comunidades de origem,

Nas diversas cidades do Brasil.

Independente donde estejamos vivendo,

Somos indígenas do mundo contemporâneo.

Amando nossas vidas, nossas culturas,

Nossas identidades, nossas diferenças! 